\title{
Response of Population Canopy Color Gradation Skewed Distribution Parameters of the RGB model to Micrometeorology Environment in Begonia Fimbristipula Hance
}

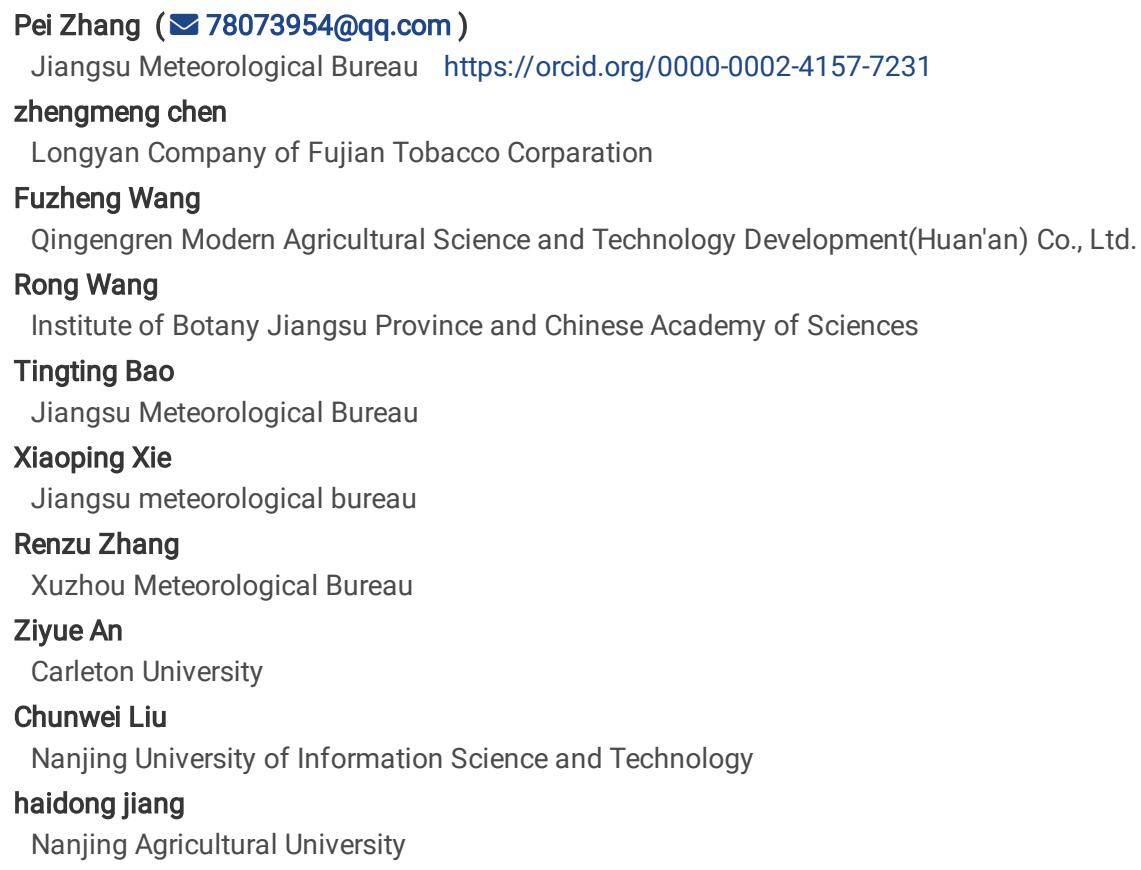

Research

Keywords: RGB model, Skewed distribution, Population canopy color gradation, Microclimate environment, Response Posted Date: April 7th, 2021

DOI: https://doi.org/10.21203/rs.3.rs-319948/v1

License: (c) (i) This work is licensed under a Creative Commons Attribution 4.0 International License. Read Full License 


\section{Abstract}

Background: The high quality and efficient production of greenhouse vegetation depend on the micrometeorology environmental adjusting such as the system warming, illumination supplement. In order to improve the quantity, quality and efficiency of greenhouse vegetation, it is necessary to figure out the relationship between the crop growth conditions and environmental meteorological factors, which could give constructive suggestions for precise control of greenhouse environment and reducing the running cost. The parameters from the color information of plant canopy reflect the internal physiological conditions, thus, RGB model has been widely used in the color analysis of digital pictures of leaves.

Results: The color scale for single leaf, single plant, and the populate canopy of Begonia Fimbristipula Hance (BFH) photographs are all have a skewed cumulative distribution histograms. The color gradation skewness-distribution (CGSD) parameters of the RGB model were increased from 4 to 20 after the skewness analysis, which greatly expanded the canopy leaf color information and could simultaneously describe the depth and distribution characteristics of canopy color. The 20 CGSD parameters were sensitive to the micrometeorology factors, especially to the radiation and temperature accumulation. The multiple regression models of mean, median, mode and kurtosis parameters to microclimate factors were established, and the spatial models of skewness parameters were optimized.

Conclusions: The models constructed based on the color gradation skewness-distribution (CGSD) parameters of the RGB model, can well explain the response of canopy color to microclimate factors and can be used to monitor the variation of plant canopy color under different micrometeorology.

\section{Background}

Meteorological conditions are crucial factors that determine the crop growth and leaf development (Zhou et al., 2020;Nawaz R. et al., 2020). Facility agriculture is an efficient crop production through the precise regulating of microclimate within the greenhouse (Kempkes et al., 2017; Amani et al., 2020; Guo et al., 2021). Clarifying the relationships between plant physiological and ecological indicators and meteorological conditions are the basis method for quantitative assessing of agro-meteorological conditions, assessing the agro-meteorological disaster losses, predicting the yield, and applying the intelligent micrometeorology control of agricultural production. Thus, it is the right path to find the determine parameters that have closely relationship with meteorological factors and reflect plant growth status sensitively.

The digital image technology is developed and the high-resolution camera equipment is widely used, the digital imaging technology has obvious advantages of high resolution and low cost in research of plant phenotype (Chen et al., 2014; He et al., 2017). Digital color image is not only convenient to obtain (Sancho-Adamson et al., 2019), but also contains abundant information about plant morphology, structure, and color gradation (Liu et al, 2015; Grosskinsky et al., 2018;Vasseur et al., 2018), which can reflect the internal status of plants. RGB color model is the popular used color representation for digital images (Barker et al., 2016). The parameters of traditional RGB model are mainly the mean values of each color channel and their combined values, which can approximately describe the color depth of the leaves and estimate the chlorophyll content of the leaves (Dey et al., 2016ロYadav et al., 2010; Adamsen et al., 1999; Hu et al., 2010; Ali et al., 2012; Han et al., 2014). Moreover, the RGB model reflects the soil moisture and nutrient level (Barbedo et al., 2019هHumplík et al., 2015aßBresson et al., 2018). However, the mean values of image parameters is not comprehensive enough in the description of color distribution (Li et al., 2014), as a result, RGB model is generally used in the studies of water, fertility and disease which may drastically change the leaf color (Neilson et al., 2015; Bai et al., 2018; Gracia-Romero et al., 2017; Sancho-Adamson et al., 2019). The RGB model is also an effective method to reflect the relationship of image information and the variation of the environmental factors.

The quantitative analysis of mega-high quality digital photographs could explain the genotype-by-environment interactions in plant phenotype (Tester $\mathrm{M}$, 2010). The variation of meteorological factors affect the physiological and biochemical characters of plants slightly, such as influencing the openness of stomata (James, 2000), changing the arrangement of the chloroplast (Min-Wha et al., 2006), and increasing or decreasing the photosynthesis rate of the leaves (Urban et al., 2017; Wang et al., 2020). All these affections change the plant color under visible spectrum (Gitelson, et al., 2003). Therefore, the image color information parameters are used as representative references to reflect meteorological environment of the growing plant. Skewed analysis expanded the RGB model parameters from the mean to the mean, median, mode, skewness and kurtosis, with the number of parameters from 4 to 20 (Chen et al., 2020). The color gradation skewness-distribution (CGSD) parameters describe leaf color information more accurately and comprehensively than the traditional mean parameters (Chen et al., 2020). Whether the color gradation distribution of single plant varies the same as the leaf, and the field scale determines its sensitivity on the response of environmental meteorological factors. The CGSD for all scales varying consistently helps to construct the effctive model between the external meteorological factors and morphological parameters of plant. The quantitative evaluation of agro-meteorological conditions for plant can be achieved by combining canopy color information indexes corresponding to different morphological parameters of plants, so as to provide information supported precise management of plant production.

Begonia Fimbristipula Hance (BFH) is a vegetation type widely used for medicine and food. BFH has abundant anthocyanins, polyphenols and flavonoids and a strong antioxidant capacity (Fukuoka et al., 2014; Ren et al., 2014; Shimizu et al., 2010a). BFH is cultivated in facilities which has warm and humid environment to ensure annual cultivation (Wu et al., 2015). After planting BFH in glass greenhouse and collecting the meteorological factors, canopy photographs, the relationship between changes in canopy color and the meteorological factors in facility environment was anlyzed. The purposes of this research are (1) quantifying the mathematical relationship between CGSD parameters and meteorological factors, and increasing the accuracy of quantifying the changes in population canopy color with meteorological changes; (2) constructing population canopy color - meteorological response models by using the relationship of CGSD parameters and meteorological factors, including temperature, humidity and solar radiation; (3) providing new methods from the RGB model to monitor the patterns of canopy color varies because of meteorological environment changes. The results may construct the crop growth model based on the CGSD parameters of RGB model, and provide a new approach for intelligent control of facility agricultural production. 


\section{Materials And Methods}

\section{Plant material and Growth conditions}

The glass greenhouse for the experiment is in Guli Modern Agriculture Demonstration Park, Jiangning District, Nanjing, Jiangsu, China (24 $\left.57^{\prime} \mathrm{N}, 116^{\circ} 30^{\prime} \mathrm{E}\right)$. The BFH were potted by rooting of cutting and planted with total nutrient matrix which was the proportion of $\mathrm{N}: \mathrm{P}_{2} \mathrm{O}_{5}: \mathrm{K}_{2} \mathrm{O}$ in $100 \mathrm{~g}$ matrix is $20: 10: 20$, trace elements include $\mathrm{Cu}, \mathrm{Fe}, \mathrm{Zn}, \mathrm{Mn}, \mathrm{B}$ and $\mathrm{Mo} \geq 1 \%$, and pH 5.85. Moreover, the matrix contains active accelerator and sustained release agent of poly-fertilizer. The BFH experiment has 2 replicates, and each replicate contains 24 pots plant. The first growing period of BFH is December 1, 2018 to February 17, 2019 , and after cutting off the $10 \mathrm{~cm}$ length top on February 18, BFH is continued growing at the second growth period from February 19, 2019 to April 11, 2019.

\section{Meteorological Data Acquisition}

Meteorological data were obtained from the agricultural meteorological observation station (DZZ4, Jiangsu Provincial Radio Science Research Institute Co., LTD., China) in the facility. The observed meteorological elements include including daily meteorological elements, such as the daily mean temperature $\left(T_{d m}\right)$, daily mean relative humidity $\left(R H_{d m}\right)$, daily mean ground temperature $\left(T_{d m}\right)$, daily mean soil temperature of $10 \mathrm{~cm}\left(T S_{d m-10 c}\right)$, daily mean vapor pressure $\left(V P_{d m}\right)$, daily mean dew point temperature $\left(T_{d m}\right)$, daily total global radiation $\left(G R_{d t}\right)$ and daily total photosynthetically active radiation $\left(P A R_{d t}\right)$. Accumulate temperature (AT), accumulate global radiation (AGR) and accumulate photosynthetically active radiation (APAR) were calculated from $T_{d m}$, $\mathrm{GR}_{\mathrm{dt}}$ and $\mathrm{PAR}_{\mathrm{dt}}$.

$$
\mathrm{AT}=\sum \mathrm{T}_{\mathrm{dm}}
$$

1

$$
A G R=\sum G_{d t}
$$

2

$$
\mathrm{APAR}=\sum \mathrm{PAR}_{\mathrm{dt}}
$$

3

\section{Canopy Image Collection}

Canopy color images of BFH were collected in facility by monitoring camera (DH-SD-65F630U-HN-Q, Zhejiang Dahua technology Co., Ltd, China) with an image resolution of $1920 \times 1080$, and the installation height was $280 \mathrm{~cm}$. The camera with vertical lens was set with fixed focal length shooting and automatic white balance and adopted fixed time shooting mode to take a photograph at set times of 9:03am every day. The 117 images from 3 groups without direct sunlight were selected for analysis, including 102 images in the first growth period (December 1, 2018 to February 17, 2019) of 2 replicates with 51 pictures each, and 15 images in the second growth period (February19, 2019 to April 11, 2019).

\section{Cutting and Denoising of the Image}

Adobe Photoshop CS software (San Jose, CA, USA) and MATLAB2016R software (referred to as MATLAB [Math Works, Natick, MA, USA]) was primarily used to cut and denoise the BFH original image.

1. Adobe Photoshop CS software (San Jose, CA, USA) was primarily used to intercept the range of $600 * 600$ in the lower left corner of the image, and the processed image was save as JPG image format (Fig.4-1).

2. The rgb2hsv function of MATLAB was used to convert RGB images into HSV images. Double cycle operation was used to set $H$ value of the image background to 0 (i.e. black), while $\mathrm{H}$ value of the plant remains unchanged. The $h s v 2 r g b$ function was used to convert the processed HSV image into RGB image (Fig.4-2).

3. Double cycle operation of MATLAB was used again to filter the color threshold value of the image processed in the previous step. The color opacity of the black part of the image was adjusted to 0 (that is, completely transparent), and the color image of the target leaf or canopy with transparent background was saved as a PNG image mode (Fig.4-3).

\section{Information Collection of the RGB Image}

Transformation of double precision arrays of image. MATLAB was used to extract and analyze BFH RGB images. After reading color images by using the imread function, the image $(:,:, 1)$, image $(:,:, 2)$, image $(:,:, 3)$, rgb2gray function were respectively used to read every pixel gradation of red, green and blue channels, as well as gray-level images. The full circulation algorithm was used to retrieve and record the non-black pixel index codes of these pixels, which were combined to an array of leaf color gradation. Then the double function was used to transform it into double precision arrays again.

Establishment of canopy color gradation skewness-distribution (CGSD) parameters table. The mean, median, mode, std, skewness and kurtosis functions were used to acquire the mean $\llbracket$ median $\square$ mode $₫$ standard Deviation $\square$ skewness and kurtosis of the double precision arrays of red, green and blue channels, as well as gray-level images(Chen et al., 2020). The CGSD parameters were obtained, including $R_{\text {Mean }}, R_{\text {Median, }}, R_{\text {Mode, }}, R_{\text {Skewness' }}, R_{\text {Kurtosis' }} G_{\text {Mean, }} G_{\text {Median }}, G_{\text {Mode' }}$ 
$\mathrm{G}_{\text {Skewness, }} \mathrm{G}_{\text {Kurtosis, }}, \mathrm{B}_{\text {Mean, }}, \mathrm{B}_{\text {Median, }}, \mathrm{B}_{\text {Mode, }}, \mathrm{B}_{\text {Skewness, }}, \mathrm{B}_{\text {Kurtosis, }} \mathrm{Y}_{\text {Mean }}, \mathrm{Y}_{\text {Median }}, \mathrm{Y}_{\text {Mode, }} \mathrm{Y}_{\text {Skewness }}$ and $\mathrm{Y}_{\text {Kurtosis, }}$. Finally, the CGSD parameters tables of color gradation distribution of BFH RGB images were formed.

Array distribution normality testing. The lillietest and jbtest functions were used to conduct the Lilliefors and Jarque-Bera tests of normal distribution for the color gradation distribution of red, green and blue channels, as well as gray-level images, of BFH RGB images.

\section{Prediction model construction and goodness of fit detection}

Correlation Analysis of 20 CGSD Parameters to Microclimate Factors. Cor package of $\mathrm{R}$ was used to analyze the relationship between 20 CGSD parameters of population canopy RGB images of $B F H$ and the corresponding microclimate factors, including daily meteorological factors $\left(T_{d m}, R H_{d m}, T G_{d m}\right.$, $T S_{d m-10 c}$, $V_{P_{d m}}, T D_{d m}, G R_{d t}$ and $P A R_{d t}$ ) and photothermal accumulation factors (AT, AGR and APAR), with double tail inspection were collected for significant examination.

Linear prediction models establishment. By using R, the linear prediction models (Y1-Y20) of 20 CGSD parameters of population canopy RGB images of $\mathrm{BFH}$ were established by a regression approach based on the least-square method, with meteorological factors as the independent variables. Probability of F-to-enter of the models was set to 0.050 or less, while Probability of F-to-remove was set to 0.100 or more. Decision coefficient optimization, significance test of regression model and regression coefficient, collinearity diagnosis of independent variables of the regression model were conducted for the alternative regression models in turn (Gai, 2000), and the optimal regression models were finally determined.

Spatial polynomial model establishment. 2 photothermal accumulation factors with the correlation coefficient of highest absolute value with CGSD parameters were selected as the independent variable, and the Spatial polynomial models (Z1-Z4) of skewness of red, green and blue channels, as well as gray-level images were established by using polynomial fitting in Curve Fitting Tool of R.

\section{Results}

\section{Skew analysis of the distribution of leaf color gradation of the RGB images}

After analyzing the cumulative distribution of color gradation of the 117 selected images of $\mathrm{BFH}$, we found that all the red, green, blue channels, and the gray-level for single leaf, single plant and population canopy images showed a left skewed distribution (Fig. 3). Lilliefors and Jarque-Bera normality tests also indicated that color gradation data did not distribute normally (Supplementary Table S1). 20 color gradient skewed distribution (CGSD) parameters were obtained including the mean, median, mode, skewness and kurtosis for the red, green, blue channels, as well as the gray-level image, for each canopy image, respectively. These parameters can describe not only the depth of canopy color but also its distribution.

The main distribution of color gradation is positive skewness for RGB channels and the gray-level image near the value of 0 . This increment of positive skewness as the canopy developing reflected that the leaf color transit from light green to dark green (Fig. 4).

\section{Correlation Analysis Microclimate Factors in Glasshouse and Population Canopy CGSD Parameters}

The relationship among 20 CGSD parameters and the microclimate factors including daily meteorological factors $\left(T_{d m}, R H_{d m}, T G_{d m}, T S_{d m}-10 c, V P_{d m}, T D_{d m}\right.$, $\mathrm{GR}_{\mathrm{dt}}$ and $P A R_{\mathrm{dt}}$ ) and accumulative factors (AT, AGR and APAR) were shown in Fig. 5. Fig. 5 indicate that temperature, humidity, ground temperature, soil temperature of $10 \mathrm{~cm}$ and solar radiation were significantly correlated with CGSD parameters. The accumulated temperature and solar radiation (AT, AGR and APAR) had extremely significant correlation with 20 CGSD parameters, with the correlation coefficients higher than 0.8 . The parameters mean, median, and mode which represented color depth showed significant positive correlation with the meteorological factors, while the parameters skewness and kurtosis represented color uniformity showed obviously negative correlation.

\section{Multiple linear relationships of the Microclimate Factors and Population Canopy CGSD Parameters}

Multiple linear relationships between population canopy CGSD parameters and microclimate factors were established by stepwise regression method using the ordinary least square method (OLS) (Table 1). Table 1 showed that all the multivariate determination coefficient $\left(R^{2}\right)$ of the population canopy colormeteorological response models equation were greater than 0.7 , indicating that the equation well explained the response of BFH population canopy CGSD parameters to microclimate factors. The $\mathrm{R}^{2}$ of the red and green channels, as well as the gray-level image, was $0.692-0.954$, which was better than those of blue channel with $0.674-0.791$. The model between the mean of green channel and accumulated temperature, daily mean relative humidity, and the daily total photosynthetically active radiation has the highest $R^{2} 0.954$. Moreover, all the models was significant $(p<0.001)$.

All the models were verified by between-group and outside-group samples ( Table 2 and Figure 6-8), which indicated that the population canopy color fitting models performed well in predicting the mean, median, mode, and the kurtosis. The accuracy of prediction of the skewness was about $80 \%$, while other CGSD parameters exceeded $90 \%$, with the mean of blue channel, as well as the gray-level image exceeded $95 \%$ (Table 2 ) in the same modeling group samples. Similarly, the accuracy of prediction of the mean, median and mode of RGB channels and the gray-level were $90 \%$, and the kurtosis was about $75 \%$, the skewness $53-58 \%$ in Between-group prediction. The accuracy of prediction of other CGSD parameters was $80 \%$ with the exception of the skewness and kurtosis of red channel, the mode and skewness of green channel, and the median of gray-level image in outside-group. Moreover, the accuracy of prediction of the kurtosis of green, blue channels and gray-level image exceeded $85 \%$. 
Although the skewness of the red, green channels, and the gray-level image perform well, the between-group and outside-group prediction accuracy were generally lower than other CGSD parameters. The skewness is non-linear to microclimate factors (Chen et al., 2020). Therefore, we fit the polynomial Z1-Z4 that incorporates spatial bidirectional patterns for the RGB channels, and the gray-level image, by taking 2 accumulation factors (the accumulate temperature $\left(x_{1}\right)$, the accumulate photosynthetically active radiation $\left(x_{5}\right)$ as the independent variables, which had the highest absolute value of the correlation coefficient.

$\mathrm{Z} 1=0.3629+0.6382 \times 10^{-3} x_{1}+2.626 \times 10^{-3} x_{5}+5.312 \times 10^{-6} x_{1}^{2}-1.072 \times 10^{-5} x_{1} x_{5}$

$Z 2=0.2242+0.5163 \times 10^{-3} x_{1}+3.11 \times 10^{-3} x_{5}+3.08 \times 10^{-6} x_{1}^{2-7.463 \times 10^{-6}} x_{1} x_{5}$

$Z 3=0.3215+0.6477 \times 10^{-3} x_{1}+2.673 \times 10^{-3} x_{5}+3.93 \times 10^{-6} x_{1}{ }^{2}-8.614 \times 10^{-6} x_{1} x_{5}$

$Z 4=0.2786+0.5116 \times 10^{-3} x_{1}+3.114 \times 10^{-3} x_{5}+4.244 \times 10^{-6} x_{1}{ }^{2}-9.285 \times 10^{-6} x_{1} x_{5}$

After comparing the multiple stepwise regression and spatial bidirectional models using the skewness, the ( $\left.R^{2}\right)$ of the spatial bidirectional models were higher than the multiple stepwise regression models with lower RMSE. It is indicated that the nonlinear models had better fitting results, or the skewness of population canopy image of BFH has close relationship to microclimate in the glass greenhouse (Table 3).

The spatial bidirectional models for the skewness has 5.7 percentage points higher accuracy in prediction, and the number of outliers significantly decreased. Compared to the regression model, the average accuracy of the spatial bidirectional models was improved by $7.63,5.75$ and 6.25 percentage points in the modeling group, between-group and outside-group, respectively. The RGB channels and gray-level image was all improved by $6.90,10.87,3.47$ and 1.72 percentage points, respectively.

\section{Discussion}

The high quality and efficient production depend on the environment regulation focusing on the plant growth in facility. The changing physiological parameters are result from variation of temperature, radiation, humidity rapidly and instantaneously (Hand, 1988;Shamshiri et al., 2018ロLi at al., 2018هChand Singh et al., 2018). Non-effectively environmental factors controlling restrict the improvement of glass greenhouse yield and crop quality (Zhang et al., 2020). Therefore, Coupling the relationship between plant growth state indicated by color parameters and meteorological factors controlling help promoting the high quality and efficiency production in facility plants, realizing the precise controlling of facility environment and decreasing the cost.

Digital color images information can reflect the growing state of plants (Vasseur et al., 2018), which provides a convenient way of plant growth monitoring. Researches on conducting qualitative and quantitative descriptions of phenotypic traits for plant appearance by using digital imaging technology are increased on smart agriculture (Chen et al., 2014). The RGB color model has been widely used to process digital color images to study chlorophyll content and its related plant nutritional status and stress response ( Zhu et al., 2019; Neilson et al., 2015; Chaerle et al., 2007). The RGB model and leaf color parameters can describe changes in tobacco leaf color depth and homogeneity (Chen et al., 2020). Now we found that images of the RGB channels, and the gray-level all showed a skewed distribution at the single leaf, plant and population canopy images scale in BFH.

Environmental changes lead to changes in the color of plants leaves (Humplik et al., 2015b; Gous et al., 2015; Cai et al., 2016; Schmalko et al., 2005; GraciaRomero et al., 2017). Our work indicated that temperature, humidity, ground temperature, soil temperature of $10 \mathrm{~cm}$ and solar radiation in glass greenhouse were significantly correlated with multiple CGSD parameters of canopy images in BFH. Moreover, the accumulative value of temperature and solar radiation (AT, AGR and APAR) had extremely significant correlation with 20 CGSD parameters, with the correlation coefficients beyond 0.8 . The mean, median, and mode parameters representing color depth has positive relationship on the accumulative parameters, while the skewness and kurtosis parameters representing the color distribution showed negative correlation with the accumulative factors significantly. The deeply canopy color of BFH images has higher accumulative factors depending on the analysis of the peak changes of the cumulative distribution diagram of canopy color and providing a new approach to quantitative the plant growing conditions.

The canopy color - meteorological responding models have high predict accuracy after calculating the image mean, median, mode and kurtosis parameters and skewness distribution using the spatial bidirectional models. The change of accumulative factors is generally linear, while skewness is calculated from higher-order function. Although the skewness was significantly related to microclimate factors, it cannot be simply described and fitted by linear fitting (Chen et al., 2020). Comparing to the multiple stepwise regression models, the spatial bidirectional models had better fitness and higher accuracy.

Digital color image has been applied to the automatic observation in agrometeorology (Shibayama et al., 2011; Sritarapipat et al., 2014), and proposed as a new technical approach that can be combined with crop growth models (Sun and Shen, 2019). Agriculture meteorological services are automatically and intelligently in future services (Yu et al., 2013; Li et al., 2016). The relationship between the CGSD parameters of the population canopy and the environment meteorological factors makes it possible to use the canopy color information to construct a plant growth model from digital images, which can provide new methods for quantitative evaluating agricultural meteorological conditions, assessing agricultural meteorological disaster loss, predicting yield and quality, and supporting precise management of crop production.

\section{Conclusion}


Analyzing the canopy images color histograms skewed distribution of BFH in glasshouse, we found 20 population canopy CGSD parameters were sensitive to the microclimate factors, especially the radiation and temperature accumulation factors. The canopy color - meteorological responding models showed that the CGSD parameters have close relationship with microclimate factors, which expands the potential application of the RGB model in monitoring the variations of plant or leaf color. The CGSD parameters can describe the canopy color information comprehensively and accurately, and consider as a new indicator for quantitative evaluating the plant growth conditions. These parameters help constructing a plant growth condition model, and providing a new method for agrometeorological assessment and prediction and ultimately supporting the precise management of crop production.

\section{Declarations}

\section{Acknowledgements}

Not applicable.

\section{Authors' contributions}

PZ and ZC are Co-first author. The work presented here was carried out in collaboration among all authors. PZ, ZC, FW, WL and HJ designed the study. PZ and RW conducted the research. ZA, TB and XX processed the data, PZ, ZC, FW and RZ analyzed the data result. PZ wrote the entire manuscript. WL and HJ edited the manuscript. All authors read and approved the final manuscript.

\section{Funding}

This study was funded by the grants from "333 project" research project for high level talent of Jiangsu Province (BRA2019348) and the National Natural Science Foundation of China (51309132).

\section{Availability of data and materials}

All datasets generated and analyzed for this study are included in the article/Supplementary Material.

\section{Ethics approval and consent to participate}

Not applicable.

\section{Consent for publication}

Not applicable.

\section{Competing interests}

The authors declare that they have no competing interests, and the research was conducted in the absence of any commercial or financial relationships that could be construed as a potential conflict of interest.

\section{References}

Adamsen, F. J., Pinter, P. J., Barnes, E. M., LaMorte, R. L., Wall, G. W., Leavitt, S. W., Kimball, B. A., 1999. Measuring wheat senescence with a digital camera. Crop Sci. 39(3), 719-724. https://doi.org/10.2135/cropsci1999.0011183X003900030019x

Ali, M. M., Al-Ani, A., Eamus, D., Tan, D. K. Y. A., 2012. New image processing based technique to determine chlorophyll in plants. American-Eurasian J. Agric. \& Environ. Sci. 12, 1323-1328. https://doi.org/10.5829/idosi.aejaes.2012.12.10.1917

Amani, M., Foroushani, S., Sultan, M., Bahrami, M., 2020. Comprehensive review on dehumidification strategies for agricultural greenhouse applications. Appl. Therm. Eng. 181. https://doi.org/10.1016/j.applthermaleng.2020.115979

Bai, G, Jenkins, S, Yuan, W, Graef, G. L., Ge, Y., 2018. Field-Based Scoring of Soybean Iron Deficiency Chlorosis Using RGB Imaging and Statistical Learning. Front. Plant Sci. 9, 1002-1011. https://doi.org/10.3389/fpls.2018.01002

Barbedo, J. G. A., 2019. Detection of nutrition deficiencies in plants using proximal images and machine learning: A review. Comput. Electron. Agr. 162, 482492. https://doi.org/10.1016/j.compag.2019.04.035

Barker, J., Zhang, N. Q., Sharon, J., Steeves, R., Wang, X., Wei, Y., Poland J., 2016. Development and evaluation of a field-based high-throughput phenotyping platform. Comput. Electron. Agr. 122, 74-85. https://doi.org/10.1016/j.compag.2016.01.017

Bresson, J., Bieker, S., Riester, L., Doll, J., Zentgraf, U., 2018. A guideline for leaf senescence analyses: from quantification to physiological and molecular investigations. J Exp Bot. 69, 769-786. https://doi.org/10.1093/jxb/erx246

Cai, J. H., Okamoto, M., Atieno, J., Sutton, T., Li, Y. L., Miklavcic, S. J., 2016. Quantifying the onset and progression of plant senescence by color image analysis for high throughput applications. PLOS One. 11(6): e0157102. https://doi.org/0.1371/journal. pone.0157102 
Chaerle, L., Hagenbeek, D., Vanrobaeys, X., Van, D. S. D., 2007. Early detection of nutrient and biotic stress in Phaseolus vulgaris. Int. J. Remote Sens. 28, 3479-3492. https://doi.org/10.1080/01431160601024259

Chand Singh, M., Singh, J. P., Kumar Pandey, S., Gladwin Cutting, N., Sharma, P., Shrivastav, V., Sharma, P., 2018. A review of three commonly used techniques of controlling greenhouse microclimate, Int. J. Curr. Microbiol. App. Sci. 7 (1), 3491-3505. https://doi.org/10.20546/ijcmas.2018.701.411.

Chen, D. J., Neumann, K., Friedel, S., Kilian, B., Chen, M., Altmann, T., et al., 2014. Dissecting the phenotypic components of crop plant growth and drought responses based on high-throughput image analysis. Plant Cell. 26, 4636-55. https://doi.org/10.1105/tpc.114.129601

Chen, Z. M., Wang, F. Z., Zhang, P., Ke, C. D., Zhu, Y., Cao, W. X., Jiang, H. D., 2020. Skewed distribution of leaf color RGB model and application of skewed parameters in leaf color description model. Plant Methods. 16, 23. https://doi.org/10.1186/s13007-020-0561-2

Dey, A. K., Sharma, M., Meshram, M. R., 2016. An analysis of leaf chlorophyll measurement method using chlorophyll meter and image processing technique. Procedia Comput. Sci. 85, 286-292. https://doi.org/10.1016/j.procs.2016.05.235

Fukuoka, N., Suzuki, T., Minamide, K., Hamada, T., 2014. Effect of shading on anthocyanin and non-flavonoid polyphenol biosynthesis of Gynura bicolor leaves in midsummer. HortScience. 49(9), 1148-1153.

Gai J. Y., 2000. Experimental statistical method. Beijing: China Agriculture Press, 2000, 193-208.

Gitelson, A.A., Gritz, Y., Merzlyak, M.N., 2003. Relationships between leaf chlorophyll content and spectral reflectance and algorithms for non-destructive chlorophyll assessment in higher plant leaves. J. Plant Physiol. 160, 271-282. https://doi.org/10.1078/0176-1617-00887

Gous, P. W., Meder, R., Fox, G. P., 2015. Near Infrared Spectral Assessment of Stay-Green Barley Genotypes under Heat Stress. J. Near Infrared Spec. 23, 145153. https://doi.org/10.1255/jnirs. 1163

Gracia-Romero, A., Kefauver ,S. C., Vergara-Diaz, O., Zaman-Allah, M. A., Prasanna, B. M., Cairns, J. E., Araus J. L., 2017. Comparative performance of ground vs. Aerially assessed RGB and multispectral indices for early-growth evaluation of maize performance under phosphorus fertilization. Front. Plant Sci. 8, 2004. https://doi.org/10.3389/fpls.2017.02004

Grosskinsky, D. K., Syaifullah, S. J., Roitsch, T., 2018. Integration of multi-omics techniques and physiological phenotyping within a holistic phenomics approach to study senescence in model and crop plants. J. Exp. Bot. 69, 825-844. https://doi.org/10.1093/jxb/erx333

Guo, Y., Zhao, H. J., Zhang, S.H., Wang, Y., Chow, D., 2021. Modeling and optimization of environment in agricultural greenhouses for improving cleaner and sustainable crop production, J. Clean. Prod. 285. https://doi.org/10.1016/j.jclepro.2020.124843

Han, W. T., Sun, Y., Xu, T. F., Chen, X. W., Su, K. O., 2014. Detecting maize leaf water status by using digital RGB images.Int. J. Agric. Biol. Eng. 7, 45-53. https://doi.org/10.3965/j.ijabe.20140701.005

Hand, D.W., 1988. Effects of atmospheric humidity on greenhouse crops. Acta Hortic. 229, 143-158, https://doi.org/10.17660/ActaHortic.1988.229.12.

He, J. Q., Harrison, R. J., Li, B., 2017. A novel 3D imaging system for strawberry phenotyping. Plant Methods, 13, 93. https://doi.org/10.1186/s13007-0170243-x

Hu, H., Liu, H. Q., Zhang, H., Zhu, J. H., Yao, X. G., Zhang, X. B., Zheng K. F., (2010). Assessment of chlorophyll content based on image colour analysis, comparison with SPAD-502. In: Proceedings of 2nd International conference on information engineering and computer Science (ICIECS), Wuhan, China. 476478. doi:10.1109/ICIECS.2010.5678413

Humplík, J. F., Lazár, D., Husičková, A., Spíchal, L., 2015a. Automated phenotyping of plant shoots using imaging methods for analysis of plant stress responses - a review. Plant Methods. 11, 29. https://doi.org/10.1186/s13007-015-0072-8

Humplík, J. F., Lazár, D., Fürst, T., Husičková, A., Hýbl, M., Spíchal, L., 2015b. Automated integrative high-throughput phenotyping of plant shoots: a case study of the cold-tolerance of pea (Pisum sativum L.). Plant Methods. 11, 20. https://doi.org/10.1186/s13007-015-0063-9

James, A. B., 2000. Responses of stomatal conductance to light, humidity and temperature in winter wheat and barley grown at three concentrations of carbon dioxide in the field. Global Change Biol. 6, 371-382. https://doi.org/10.1046/j.1365-2486.2000.00314.x

Kempkes, F., de Zwart, H.F., Munoz, P., Montero, J.I., Baptista, F.J., Giuffrida, F., Gilli, C., Stepowska, A., Stanghellini, C., 2017. Heating and dehumidification in production greenhouses at northern latitudes: energy use, Acta Hortic. 1164, 445-452. https://doi.org/10.17660/ActaHortic.2017.1164.58.

Li, G., Tang, L., Zhang, X., Dong, J., Xiao, M., 2018. Factors affecting greenhouse microclimate and its regulating techniques: a review, IOP Conf. Ser.: Earth Environ. Sci. 167, 012019, https://doi.org/10.1088/1755-1315/167/1/012019.

Li, L., Zhang, Q., Huang, D., 2014. A review of imaging techniques for plant phenotyping. Sensors-Basel. 14, 20078-20111. https://doi.org/428 $10.3390 /$ s 141120078 
Liu, Z.Q, Hu, H. B., Yu, H., Yang, X., Yang, H. L., Ruan, C. X., Wang, Y., Tang, J. W., 2015. Relationship between leaf physiological traits and canopy color indices during the spring leaf-expansion period in an oak forest. Ecosphere. 259, 1-9. https://doi.org/10.1890/ES14-00452.1.

Li,Y. N., Cao, Z. G., Lu H., Xiao Y., Zhu,Y. J., Cremers, A. B., 2016. In-field cotton detection via region-based semantic image segmentation. Comput. Electron. Agr. 127, 475-486. https://doi.org/10.1016/j.compag.2016.07.006

Min-Wha, J., Mohammad, B. A., Eun-Joo, H., Kee-Yoeup, P., 2006. Photosynthetic pigments, morphology and leaf gas exchange during ex vitro acclimatization of micropropagated CAM Doritaenopsis plantlets under relative humidity and air temperature. Environ. Exp. Bot. 55, 183-194. https://doi.org/10.1016/j.envexpbot.2004.10.014

Nawaz, R., Abbasi, N. A., Hafiz, I. A., Khalid, A, 2020. Impact of climate variables on growth and development of Kinnow fruit (Citrus nobilis Lour x Citrus deliciosa Tenora) grown at different ecological zones under climate change scenario. Sci. Hortic-Amsterdam. 260.

https://doi.org/10.1016/j.scienta.2019.108868

Neilson, E. H., Edwards, A. M., Blomstedt, C. K., Berger, B., Moller, B. L., Gleadow, R. M., 2015. Utilization of a high-throughput shoot imaging system to examine the dynamic phenotypic responses of a C4 cereal crop plant to nitrogen and water deficiency over time. J Exp Bot. 66(7), 1817-1832.

https://doi.org/10.1093/jxb/eru526

Ren, J., Guo, S. S., Xin, X. L., Chen, L., 2014. Changes in volatile constituents and phenols from Gynura bicolor DC grown in elevated CO2 and LED lighting. Sci. Hortic-Amsterdam. 175, 243-250. https://doi.org/ 10.1016/j.scienta.2014.06.023

Sancho-Adamson, M., Trillas, M. I., Bort, J., Fernandez-Gallego, J. A., Romanyà, J., 2019. Use of RGB Vegetation Indexes in Assessing Early Effects of Verticillium Wilt of Olive in Asymptomatic Plants in High and Low Fertility Scenarios. Remote Sens. 11, 607. https:// doi.org/10.3390/rs11060607

Schmalko, M. E., Scipioni, P. G., Ferreyra, D. J., 2005. Effect of water activity and temperature in color and chlorophylls changes in Yerba Mate leaves. Int. J Food Prop. 8, 313-322. https://doi.org/10.1081/JFP-200060250

Shamshiri, R. R., Jones, J.W., Thorp, K.R., Ahmad, D., Man, H.C., Taheri, S., 2018. Review of optimum temperature, humidity, and vapour pressure deficit for microclimate evaluation and control in greenhouse cultivation of tomato: a review, Int. Agrophys. 32 (2), 287-302. https://doi.org/10.1515/intag-2017-0005

Shibayama, M., Sakamoto, T., Takada, E., Inoue, A., Morita, K., Takahashi, W., Kimura, A., 2011. Estimating paddy rice leaf area index with fixed point continuous observation of near infrared reflectance using a calibrated digital camera. J. Plant Prod. Sci. 14(1), 30-46. https://doi.org/10.1626/pps.14.30

Shimizu, Y., Maeda K., Kato M., Shimomura K., 2010a. Methyl jasmonate induces anthocyanin accumulation in Gynura bicolor cultured roots. In Vitro Cell Dev Biol Plant, 46, 460-465. https://doi.org/ 10.1007/s11627-010-9294-7

Sritarapipat, T., Rakwatin P., Kasetkasem, T., 2014. Automatic Rice Crop Height Measurement Using a Field Server and Digital Image Processing. Sensors, 14, 900-926. https://doi.org/10.3390/s140100900

Sun Y. Y., Shen S. H., 2019. Research progress in application of crop growth models. Chinese Journal of Agrometeorology, 40(7): 444-459. http s://doi.org/10.3969/j.issn.1000-6362.2019.07.004

Tester, M., Langridge P., 2010. Breeding technologies to increase crop production in a changing world. Science. 327: 818-822. https://doi.org/10.1126/science. 1183700

Urban, J., Ingwers, M.W., Mcguire, M.A., Teskey, R.O., 2017. Increase in leaf temperature opens stomata and decouples net photosynthesis from stomatal conductance in Pinus taeda and Populus deltoides x nigra. J. Exp. Bot. 68, 1757-1767. https://doi.org/10.1093/jxb/erx052

Vasseur, F., Bresson, J., Wang, G., Schwab, R., Weigel, D., 2018. Image-based methods for phenotyping growth dynamics and fitness components in Arabidopsis thaliana. Plant Methods. 14, 63. https://doi.org/https://doi.org/10.1101/208512

Wang, B., Cai, W. W., Li, J. L., Wan, Y. F., Li, Y. E., Guo, C., Wilkes, A., You, S. C., Qin, X. B., Liu, K. W., 2020. Leaf photosynthesis and stomatal conductance acclimate to elevated [CO2] and temperature thus increasing dry matter productivity in a double rice cropping system. Field Crop. Res. $248,107735$. https://doi.org/10.1016/j.fcr.2020.107735

Wu, C. C., Chang, Y. P., Wang, J. J., Liu, C. H., Wong, S. L., Jiang, C. M., Hsieh, S. L., 2015. Dietary administration of Gynura bicolor (Roxb. Willd.) DC water extract enhances immune response and survival rate against Vibrio alginolyticus and white spot syndrome virus in white shrimp Litopeneaus vannamei. Fish Shellfish Immun. 42(1) :25-33. https://doi.org/10.1016/j.fsi.2014.10.016

Yadav, S. P., Ibaraki, Y., Dutta, G. S., 2010. Estimation of the chlorophyll content of micropropagated potato plants using RGB based image analysis. Plant Cell Tiss. Org. 100, 183-188. doi:10.1007/s11240-009-9635-6

Yu, Z.H., Cao. Z. G., Wu X., Bai X. D., Qin Y. M., Zhuo W., Xiao Y., Zhang X. F., Xue H. X., 2013. Automatic image-based detection technology for two critical growth stages of maize: Emergence and three-leaf stage. Agr. Forest Meteorol. 174-175: 65-84. http://dx.doi.org/10.1016/j.agrformet.2013.02.011 
Zhang, S. H., Guo, Y., Zhao, H. J., Wang, Y., Chow, D., Fang, Y., 2020. Methodologies of control strategies for improving energy efficiency in agricultural greenhouses. J. Clean. Prod. 274. https://doi.org/10.1016/j.jclepro.2020.122695

Zhou, H. L., Zhou, G. S., He, Q. J., Zhou, L., Ji, Y. H., Zhou, M. Z., 2020. Environmental explanation of maize specific leaf area under varying water stress regimes. Environ. Exp. Bot. 171, 103932. https://doi.org/10.1016/j.envexpbot.2019.103932

Zhu, J., Deng, J., Shi, Y., Chen, Z., Han, N., Wang, K., 2009. Diagnoses of rice nitrogen status based on characteristics of scanning leaf. Spectrosc. Spect. Anal. 29: 2171-2175. doi:10.3964/j.issn.1000-0593(2009)08-2171-05

\section{Tables}

Table 1 Population canopy color-meteorological response models of BFH and their goodness of fit

\begin{tabular}{|c|c|c|c|c|c|c|}
\hline Model & & R-square & Adjusted R-square & RMSE & F value & Significance $\mathrm{F}$ \\
\hline $\mathrm{R}_{\text {Mean }}$ & $Y 1=11.556-0.017 x_{1}+0.524 x_{2}+0.549 x_{3}$ & 0.848 & 0.839 & 2.456 & 87.634 & 0.000 \\
\hline $\mathrm{R}_{\text {Median }}$ & $Y 2=-28.395-0.015 x_{1}+0.629 x_{2}+0.703 x_{3}+1.871 x_{4}$ & 0.868 & 0.857 & 2.630 & 75.860 & 0.000 \\
\hline $\mathrm{R}_{\text {Mode }}$ & $Y 3=14.284-0.024 x_{5}+2.596 x_{4}$ & 0.746 & 0.735 & 3.668 & 70.458 & 0.000 \\
\hline $\mathrm{R}_{\text {Skewness }}$ & $Y 4=2.100+0.001 x_{1}-0.199 x_{4}+0.107 x_{6}$ & 0.803 & 0.791 & 0.142 & 63.968 & 0.000 \\
\hline $\mathrm{R}_{\text {Kurtosis }}$ & $Y 5=5.371-0.010 x_{1}-0.024 x_{>}-0.028 x_{2}$ & 0.706 & 0.688 & 0.382 & 37.703 & 0.000 \\
\hline $\mathrm{G}_{\text {Mean }}$ & $Y 6=27.424-0.022 x_{1}+0.464 x_{2}+0.349 x_{3}$ & 0.954 & 0.954 & 1.609 & 327.337 & 0.000 \\
\hline $\mathrm{G}_{\text {Median }}$ & $Y 7=34.402-0.036 x_{5}+0.366 x_{2}$ & 0.906 & 0.902 & 2.548 & 230.359 & 0.000 \\
\hline $\mathrm{G}_{\text {Mode }}$ & $Y 8=30.294-0.037 x_{5}+0.342 x_{2}$ & 0.845 & 0.839 & 3.456 & 130.821 & 0.000 \\
\hline $\mathrm{G}_{\text {Skewness }}$ & $Y 9=1.501+0.030 x_{5}-0.052 x_{7}-0.013 x_{2}$ & 0.831 & 0.820 & 0.138 & 76.900 & 0.000 \\
\hline $\mathrm{G}_{\text {Kurtosis }}$ & $\mathrm{Y} 10=2.824+0.002 x_{1}$ & 0.732 & 0.726 & 0.310 & 133.539 & 0.000 \\
\hline $\mathrm{B}_{\text {Mean }}$ & $Y 11=30.430-0.013 x_{1}+0.341 x_{2}$ & 0.703 & 0.691 & 3.136 & 56.787 & 0.000 \\
\hline $\mathrm{B}_{\text {Median }}$ & $Y 12=-6.307-0.012 x_{1}+0.380 x_{2}+2.094 x_{4}$ & 0.752 & 0.736 & 3.470 & 47.483 & 0.000 \\
\hline B $_{\text {Mode }}$ & $Y 13=4.464-0.020 x_{5}+3.267 x_{4}$ & 0.695 & 0.683 & 4.028 & 54.781 & 0.000 \\
\hline$B_{\text {Skewness }}$ & $\mathrm{Y} 14=1.716+0.001 x_{1}-0.083 x_{4}$ & 0.791 & 0.782 & 0.145 & 90.164 & 0.000 \\
\hline B Kurtosis $_{1}$ & $\mathrm{Y} 15=2.874+0.002 x_{1}$ & 0.674 & 0.668 & 0.346 & 101.377 & 0.000 \\
\hline $\mathrm{Y}_{\text {Mean }}$ & $\mathrm{Y} 16=38.927-0.019 x_{1}+0.307 x_{2}$ & 0.892 & 0.888 & 2.240 & 198.372 & 0.000 \\
\hline $\mathrm{Y}_{\text {Median }}$ & $\mathrm{Y} 17=30.819-0.021 x_{1}+0.368 x_{2}$ & 0.855 & 0.848 & 2.956 & 140.973 & 0.000 \\
\hline $\mathrm{Y}_{\text {Mode }}$ & $Y 18=26.665-0.032 x_{5}+2.144 x_{4}$ & 0.825 & 0.818 & 3.440 & 113.213 & 0.000 \\
\hline$Y_{\text {Skewness }}$ & $\mathrm{Y} 19=1.818+0.001 x_{1}-0.092 x_{4}$ & 0.784 & 0.775 & 0.156 & 87.302 & 0.000 \\
\hline $\mathrm{Y}_{\text {Kurtosis }}$ & $Y 20=2.901+0.002 x_{1}$ & 0.692 & 0.686 & 0.355 & 110.029 & 0.000 \\
\hline
\end{tabular}

Note $\varangle x_{7}$ is the accumulate temperature, $x_{2}$ is the daily mean relative humidity, $x_{3}$ is the daily total photosynthetically active radiation, $x_{4}$ is the daily mean soil temperature of $10 \mathrm{~cm}, x_{5}$ is the accumulate photosynthetically active radiation, $x_{6}$ is the daily minimum ground temperature, $x_{7}$ is the accumulate global radiation. 9

Table 2 Analytical results of prediction accuracy of population canopy color-meteorological response models 


\begin{tabular}{|c|c|c|c|c|c|c|c|c|c|c|c|}
\hline \multicolumn{2}{|c|}{ Model } & \multicolumn{3}{|c|}{ Modeling group } & \multicolumn{3}{|c|}{ Between-group prediction } & \multicolumn{3}{|c|}{ Outside-group prediction } & \multirow{2}{*}{ Average } \\
\hline & & $\begin{array}{l}\text { Prediction } \\
\text { sample } \\
\text { data }\end{array}$ & $\begin{array}{l}\text { Eliminate } \\
\text { abnormal } \\
\text { data }\end{array}$ & $\begin{array}{l}\text { Predictive } \\
\text { accuracy }\end{array}$ & $\begin{array}{l}\text { Prediction } \\
\text { sample } \\
\text { data }\end{array}$ & $\begin{array}{l}\text { Eliminate } \\
\text { abnormal } \\
\text { data }\end{array}$ & $\begin{array}{l}\text { Predictive } \\
\text { accuracy }\end{array}$ & $\begin{array}{l}\text { Prediction } \\
\text { sample } \\
\text { data }\end{array}$ & $\begin{array}{l}\text { Eliminate } \\
\text { abnormal } \\
\text { data }\end{array}$ & $\begin{array}{l}\text { Predictive } \\
\text { accuracy }\end{array}$ & \\
\hline $\begin{array}{l}R \\
\square \\
\square\end{array}$ & $Y_{1}$ & 51 & 0 & $96.27 \%$ & 51 & 0 & $92.89 \%$ & 15 & 0 & $90.92 \%$ & $94.11 \%$ \\
\hline $\begin{array}{l}\mathrm{R} \\
\square \\
\square \\
\square\end{array}$ & $Y_{2}$ & 51 & 0 & $96.02 \%$ & 51 & 0 & $91.98 \%$ & 15 & 0 & $84.90 \%$ & $92.84 \%$ \\
\hline $\begin{array}{l}R \\
\square \\
\square\end{array}$ & $\mathrm{Y}_{3}$ & 51 & 0 & $92.89 \%$ & 51 & 0 & $92.47 \%$ & 15 & 0 & $87.87 \%$ & $92.06 \%$ \\
\hline $\begin{array}{l}R \\
0 \\
0\end{array}$ & $\mathrm{Y}_{4}$ & 51 & 0 & $80.98 \%$ & 51 & 10 & $53.21 \%$ & 15 & 3 & $70.30 \%$ & $68.80 \%$ \\
\hline $\begin{array}{l}R \\
\square \\
\square\end{array}$ & $Y_{5}$ & 51 & 0 & $90.48 \%$ & 51 & 0 & $72.53 \%$ & 15 & 0 & $73.56 \%$ & $80.49 \%$ \\
\hline $\begin{array}{l}G \\
\square \\
\square\end{array}$ & $Y_{6}$ & 51 & 0 & $97.98 \%$ & 51 & 0 & $93.55 \%$ & 15 & 0 & $93.71 \%$ & $95.50 \%$ \\
\hline $\begin{array}{l}\text { G } \\
0 \\
0 \\
\square\end{array}$ & $Y_{7}$ & 51 & 0 & $96.29 \%$ & 51 & 0 & $91.97 \%$ & 15 & 0 & $80.08 \%$ & $92.33 \%$ \\
\hline $\begin{array}{l}G \\
\square \\
\square\end{array}$ & $Y_{8}$ & 51 & 0 & $94.14 \%$ & 51 & 0 & $92.38 \%$ & 15 & 0 & $77.33 \%$ & $91.22 \%$ \\
\hline $\begin{array}{l}G \\
\square \\
\square\end{array}$ & $Y_{9}$ & 51 & 1 & $76.29 \%$ & 51 & 9 & $52.40 \%$ & 15 & 7 & $35.12 \%$ & $63.73 \%$ \\
\hline $\begin{array}{l}G \\
0 \\
\square\end{array}$ & $Y_{10}$ & 51 & 0 & $92.98 \%$ & 51 & 0 & $76.64 \%$ & 15 & 0 & $86.75 \%$ & $85.06 \%$ \\
\hline $\begin{array}{l}B \\
0 \\
\square\end{array}$ & $Y_{11}$ & 51 & 0 & $95.46 \%$ & 51 & 0 & $92.05 \%$ & 15 & 0 & $84.66 \%$ & $92.59 \%$ \\
\hline $\begin{array}{l}B \\
0 \\
0 \\
\square\end{array}$ & $Y_{12}$ & 51 & 0 & $94.53 \%$ & 51 & 0 & $90.57 \%$ & 15 & 0 & $85.42 \%$ & $91.64 \%$ \\
\hline $\begin{array}{l}B \\
\square \\
\square\end{array}$ & $Y_{13}$ & 51 & 0 & $92.66 \%$ & 51 & 0 & $92.65 \%$ & 15 & 0 & $84.46 \%$ & $91.60 \%$ \\
\hline $\begin{array}{l}B \\
0 \\
\square\end{array}$ & $\mathrm{Y}_{14}$ & 51 & 1 & $82.21 \%$ & 51 & 8 & $56.11 \%$ & 15 & 3 & $82.39 \%$ & $72.36 \%$ \\
\hline $\begin{array}{l}B \\
\square \\
\square\end{array}$ & $Y_{15}$ & 51 & 0 & $92.17 \%$ & 51 & 0 & $74.21 \%$ & 15 & 0 & $84.12 \%$ & $83.31 \%$ \\
\hline $\begin{array}{l}Y \\
\square \\
\square\end{array}$ & $Y_{16}$ & 51 & 0 & $96.95 \%$ & 51 & 0 & $93.33 \%$ & 15 & 0 & $89.60 \%$ & $94.43 \%$ \\
\hline $\begin{array}{l}Y \\
Q \\
0 \\
0\end{array}$ & $Y_{17}$ & 51 & 0 & $90.26 \%$ & 51 & 0 & $93.64 \%$ & 15 & 0 & $67.68 \%$ & $88.84 \%$ \\
\hline $\begin{array}{l}Y \\
Q \\
\square\end{array}$ & $\mathrm{Y}_{18}$ & 51 & 0 & $94.11 \%$ & 51 & 0 & $93.15 \%$ & 15 & 0 & $87.27 \%$ & $92.82 \%$ \\
\hline $\begin{array}{l}Y \\
Q \\
\square\end{array}$ & $Y_{19}$ & 51 & 2 & $80.43 \%$ & 51 & 10 & $58.03 \%$ & 15 & 3 & $84.64 \%$ & $73.81 \%$ \\
\hline Y & $\mathrm{Y}_{20}$ & 51 & 0 & $92.56 \%$ & 51 & 0 & $76.04 \%$ & 15 & 0 & $86.53 \%$ & $84.59 \%$ \\
\hline
\end{tabular}

Page 10/17 
Note: Predictive accuracy $=(1-\mid$ predictive value-measured value $\mid /$ measured $) * 100 \%$

Table 3 Comparison of multiple stepwise regression models and spatial bidirectional models for the skewness

\begin{tabular}{|c|c|c|c|c|c|}
\hline Parameters & Model & R-square & $\begin{array}{l}\text { Adjusted } \\
\text { R-square }\end{array}$ & RMSE & Significant \\
\hline \multirow[t]{2}{*}{$\mathrm{R}_{\text {Skewness }}$} & Y4 & 0.803 & 0.791 & 0.142 & 0.000 \\
\hline & Z1 & 0.884 & 0.874 & 0.111 & 0.000 \\
\hline \multirow[t]{2}{*}{$\mathrm{G}_{\text {Skewness }}$} & Y9 & 0.831 & 0.820 & 0.138 & 0.000 \\
\hline & $\mathrm{Z2}$ & 0.902 & 0.893 & 0.107 & 0.000 \\
\hline \multirow[t]{2}{*}{$B_{\text {Skewness }}$} & Y14 & 0.791 & 0.782 & 0.145 & 0.000 \\
\hline & Z3 & 0.900 & 0.891 & 0.102 & 0.000 \\
\hline \multirow[t]{2}{*}{$Y_{\text {Skewness }}$} & Y19 & 0.784 & 0.775 & 0.156 & 0.000 \\
\hline & Z4 & 0.894 & 0.884 & 0.111 & 0.000 \\
\hline
\end{tabular}

Table 4 Comparison of the prediction accuracy of the multiple stepwise regression models and spatial bidirectional models for the skewness

\begin{tabular}{|c|c|c|c|c|c|c|c|c|c|c|c|}
\hline \multirow[t]{2}{*}{ Parameters } & \multirow[t]{2}{*}{ Model } & \multicolumn{2}{|c|}{ Modeling group } & \multicolumn{2}{|c|}{ Between-group } & \multicolumn{4}{|c|}{ Outside-group } & \multirow[b]{2}{*}{$\begin{array}{l}\text { Predictive } \\
\text { accuracy }\end{array}$} & \multirow[t]{2}{*}{ Average } \\
\hline & & $\begin{array}{l}\text { Prediction } \\
\text { sample } \\
\text { data }\end{array}$ & $\begin{array}{l}\text { Eliminate } \\
\text { abnormal } \\
\text { data }\end{array}$ & $\begin{array}{l}\text { Predictive } \\
\text { accuracy }\end{array}$ & $\begin{array}{l}\text { Prediction } \\
\text { sample } \\
\text { data }\end{array}$ & $\begin{array}{l}\text { Eliminate } \\
\text { abnormal } \\
\text { data }\end{array}$ & $\begin{array}{l}\text { Predictive } \\
\text { accuracy }\end{array}$ & $\begin{array}{l}\text { Prediction } \\
\text { sample } \\
\text { data }\end{array}$ & $\begin{array}{l}\text { Eliminate } \\
\text { abnormal } \\
\text { data }\end{array}$ & & \\
\hline \multirow[t]{2}{*}{$\mathrm{R}_{\text {Skewness }}$} & Y4 & 51 & 0 & $80.98 \%$ & 51 & 10 & $53.21 \%$ & 15 & 3 & $70.30 \%$ & $68.80 \%$ \\
\hline & $\mathrm{Z1}$ & 51 & 0 & $90.02 \%$ & 51 & 1 & $60.56 \%$ & 15 & 3 & $75.58 \%$ & $77.76 \%$ \\
\hline \multirow[t]{2}{*}{$\mathrm{G}_{\text {Skewness }}$} & Y9 & 51 & 1 & $76.29 \%$ & 51 & 9 & $52.40 \%$ & 15 & 7 & $35.12 \%$ & $63.73 \%$ \\
\hline & $\mathrm{Z2}$ & 51 & 0 & $88.31 \%$ & 51 & 1 & $60.82 \%$ & 15 & 3 & $73.71 \%$ & $74.60 \%$ \\
\hline \multirow[t]{2}{*}{$\mathrm{B}_{\text {Skewness }}$} & Y14 & 51 & 1 & $82.21 \%$ & 51 & 8 & $56.11 \%$ & 15 & 3 & $82.39 \%$ & $72.36 \%$ \\
\hline & Z3 & 51 & 0 & $90.16 \%$ & 51 & 1 & $61.27 \%$ & 15 & 3 & $75.61 \%$ & $75.83 \%$ \\
\hline \multirow[t]{2}{*}{$Y_{\text {Skewness }}$} & Y19 & 51 & 2 & $80.43 \%$ & 51 & 10 & $58.03 \%$ & 15 & 3 & $84.64 \%$ & $73.81 \%$ \\
\hline & Z4 & 51 & 0 & $89.05 \%$ & 51 & 1 & $60.10 \%$ & 15 & 3 & $82.34 \%$ & $75.53 \%$ \\
\hline
\end{tabular}

\section{Figures}




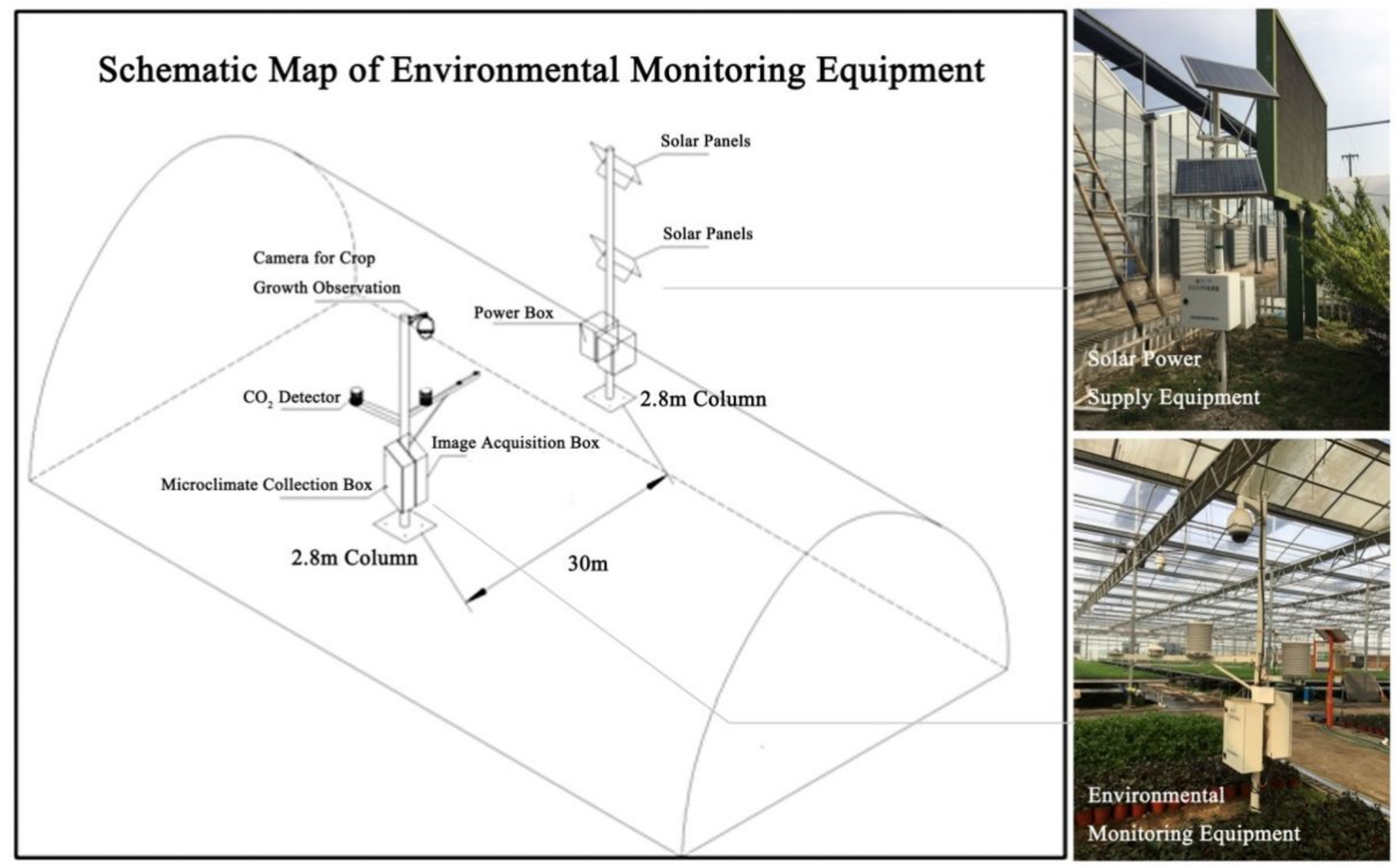

Figure 1

Schematic map of microclimate observation and digital camera in the glass greenhouse 


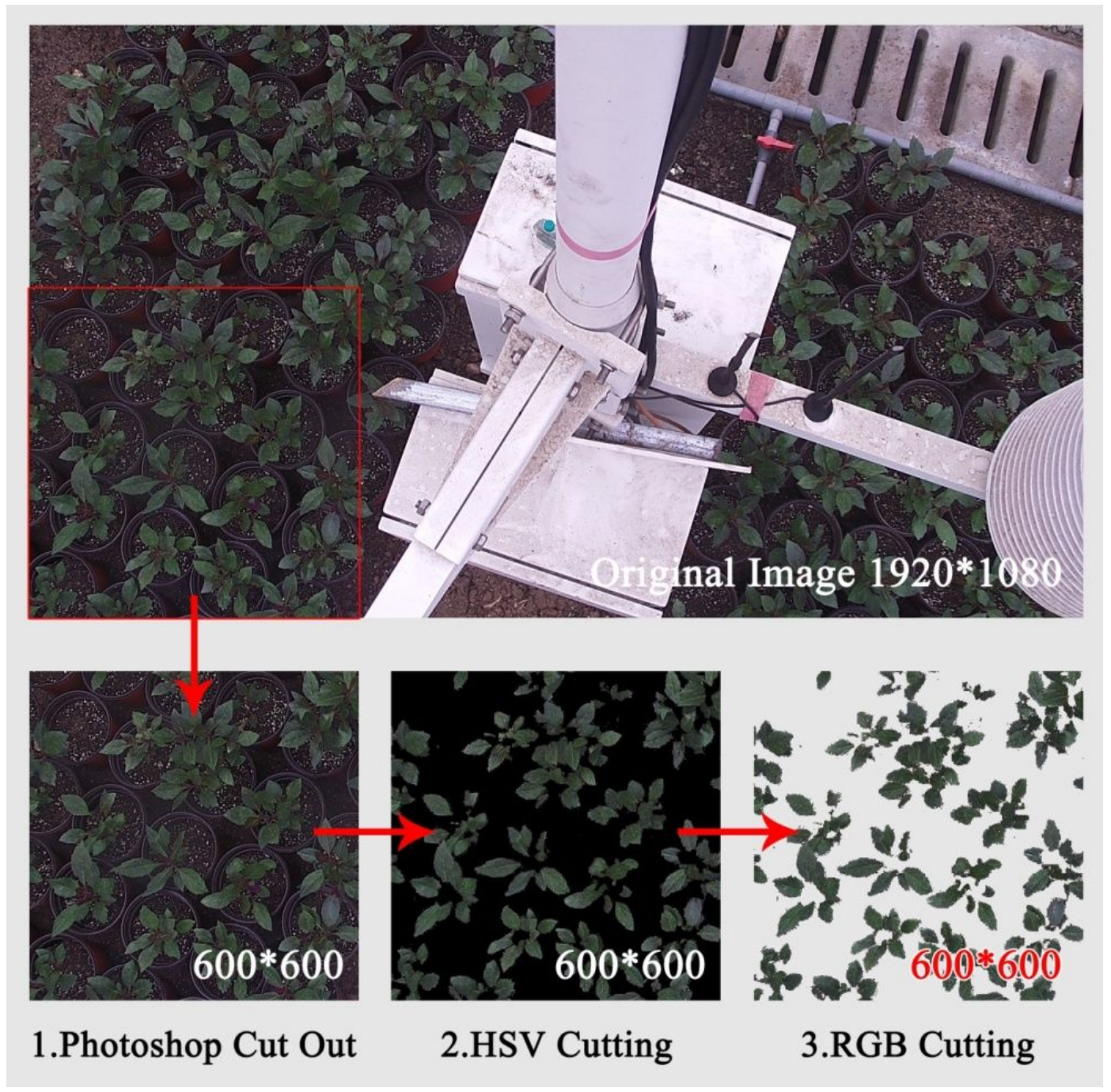

Figure 2

Flow map of Cutting and Denoising of the Image

Red Channel Green Channel Blue Channel Gray Image

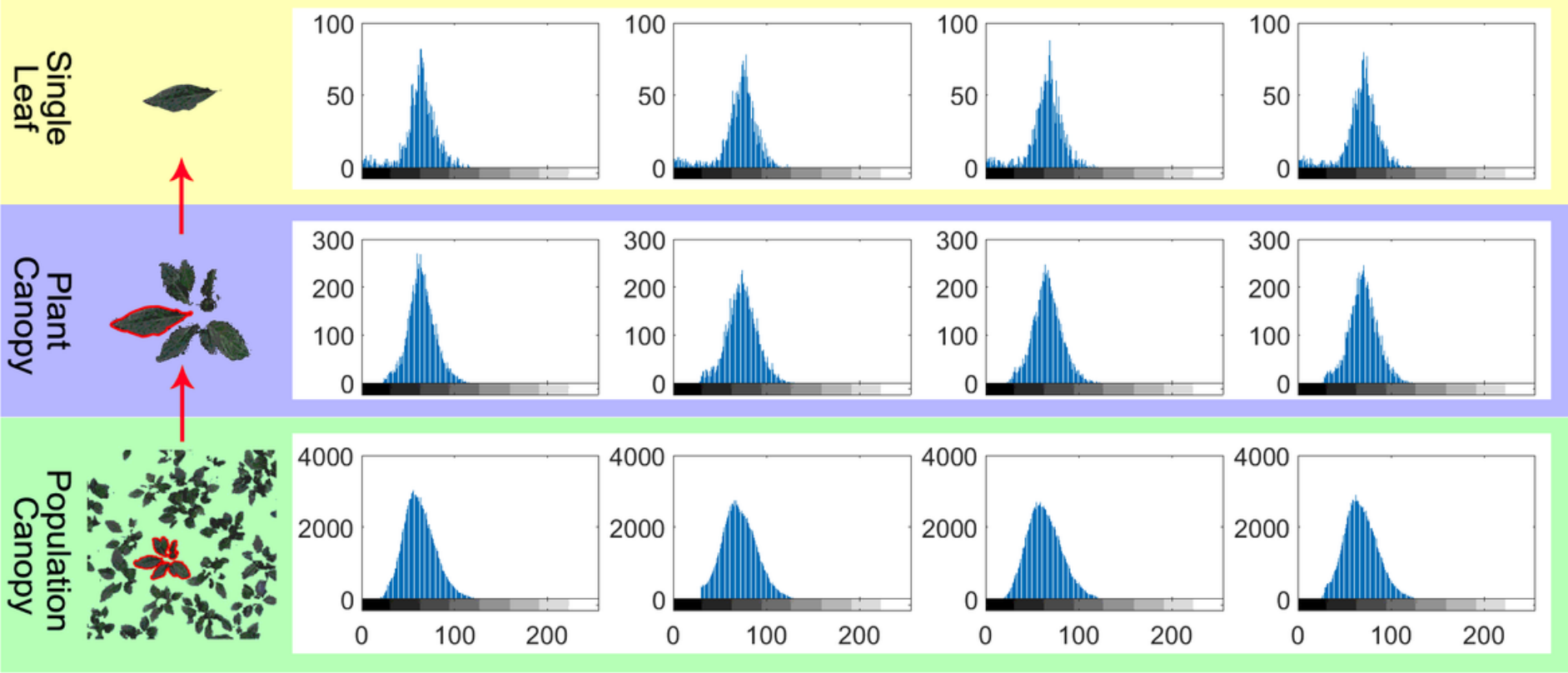


RGB model color gradation distribution of single leaf, plant canopy and population canopy images of BFH. The cumulative frequency histogram of red, green and blue channels, as well as gray-level images, were drawn using the imhist function of MATLAB.. The X-axis is the color gradation value, and the $\mathrm{Y}$ axis is the cumulative frequency,

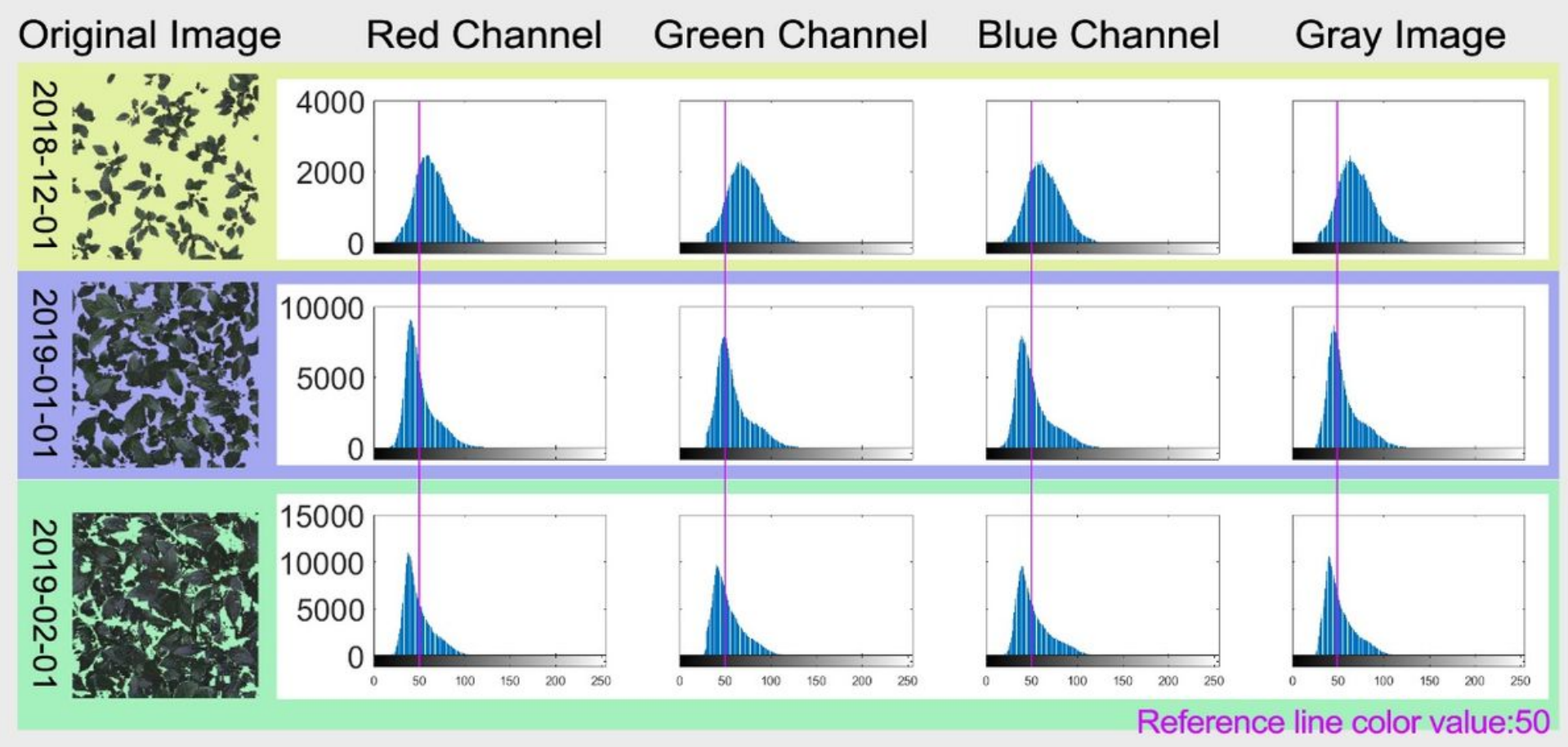

Figure 4

RGB model color gradation distribution of population canopy images of BFH on 3 different dates. The cumulative frequency histogram of red, green and blue channels, as well as gray-level images, were drawn using the imhist function of MATLAB. The X-axis is the color gradation value, and the Y-axis is the cumulative frequency,

\begin{tabular}{|c|c|c|c|c|c|c|c|c|c|c|c|}
\hline & $\mathrm{T}_{\mathrm{dm}}$ & $\mathrm{RH}_{\mathrm{dm}}$ & $T G_{d m}$ & $\mathrm{TS}_{\mathrm{dm}-10 \mathrm{c}}$ & $\mathrm{VP}_{\mathrm{dm}}$ & $\mathrm{TD}_{\mathrm{dm}}$ & $\mathrm{GR}_{\mathrm{dt}}$ & $\mathrm{PAR}_{\mathrm{dt}}$ & AT & AGR & APAR \\
\hline $\mathbf{R}_{\text {Mean }}$ & -0.249 & $0.606^{\star \star}$ & $0.278^{\star}$ & $0.629^{\star *}$ & -0.025 & -0.029 & -0.240 & -0.251 & $-0.865^{\star \star}$ & $-0.856^{\star \star}$ & $-0.860^{\star \star}$ \\
\hline $\mathbf{R}_{\text {Median }}$ & -0.253 & $0.605^{\star \star}$ & $0.280^{*}$ & $0.641^{\star *}$ & -0.024 & -0.033 & -0.227 & -0.235 & $-0.843^{\star *}$ & $-0.836^{\star \star}$ & $-0.840^{\star \star}$ \\
\hline $\mathbf{R}_{\text {Mode }}$ & -0.257 & $0.584^{\star \star}$ & $0.315^{*}$ & $0.690^{* *}$ & -0.041 & -0.045 & -0.247 & -0.251 & $-0.815^{\star *}$ & $-0.813^{\star \star}$ & $-0.816^{\star *}$ \\
\hline $\mathbf{R}_{\text {Skewness }}$ & 0.225 & $-0.586^{\star \star}$ & $-0.292^{*}$ & $-0.641^{* *}$ & 0.003 & 0.010 & 0.214 & 0.224 & $0.853^{\star *}$ & $0.846^{\star *}$ & $0.850^{* *}$ \\
\hline $\mathbf{R}_{\text {Kurtosis }}$ & 0.142 & $-0.503^{\star \star}$ & -0.265 & $-0.519^{\star *}$ & -0.054 & -0.047 & 0.113 & 0.131 & $0.792^{\star \star}$ & $0.774^{\star \star}$ & $0.779^{* *}$ \\
\hline $\mathrm{G}_{\text {Mean }}$ & $-0.282^{\star}$ & $0.633^{\star \star}$ & 0.236 & $0.588^{\star \star}$ & -0.067 & -0.053 & $-0.344^{*}$ & $-0.358^{\star *}$ & $-0.950^{\star \star}$ & $-0.947^{\star \star}$ & $-0.949^{\star \star}$ \\
\hline $\mathrm{G}_{\text {Median }}$ & $-0.289^{\star}$ & $0.641^{\star \star}$ & 0.246 & $0.613^{\star \star}$ & -0.068 & -0.057 & $-0.343^{*}$ & $-0.355^{\star}$ & $-0.931^{\star *}$ & $-0.929^{* *}$ & $-0.931^{\star *}$ \\
\hline $\mathrm{G}_{\text {Mode }}$ & $-0.295^{\star}$ & $0.607^{\star \star}$ & 0.250 & $0.623^{\star \star}$ & -0.088 & -0.079 & $-0.326^{*}$ & $-0.334^{*}$ & $-0.901^{\star \star}$ & $-0.901^{\star \star}$ & $-0.902^{\star \star}$ \\
\hline $\mathrm{G}_{\text {Skewness }}$ & 0.231 & $-0.598^{\star *}$ & $-0.307^{*}$ & $-0.668^{\star \star}$ & 0.008 & 0.010 & 0.257 & 0.268 & $0.866^{\star *}$ & $0.864^{\star \star}$ & $0.867^{* *}$ \\
\hline $\mathrm{G}_{\text {Kurtosis }}$ & 0.157 & $-0.507^{\star \star}$ & -0.261 & $-0.526^{\star \star}$ & -0.031 & -0.033 & 0.176 & 0.197 & $0.855^{\star \star}$ & $0.844^{\star \star}$ & $0.848^{\star *}$ \\
\hline $\mathbf{B}_{\text {Mean }}$ & $-0.332^{\star}$ & $0.625^{\star \star}$ & 0.235 & $0.632^{\star \star}$ & -0.105 & -0.112 & $-0.284^{*}$ & $-0.293^{\star}$ & $-0.794^{\star \star}$ & $-0.789^{\star \star}$ & $-0.793^{\star \star}$ \\
\hline $\mathbf{B}_{\text {Median }}$ & $-0.317^{\star}$ & $0.619^{* *}$ & 0.252 & $0.654^{* *}$ & -0.088 & -0.097 & -0.272 & $-0.278^{\star}$ & $-0.790^{\star *}$ & $-0.787^{\star *}$ & $-0.790^{\star \star}$ \\
\hline $\mathrm{B}_{\text {Mode }}$ & -0.263 & $0.577^{\star \star *}$ & $0.321^{*}$ & $0.716^{\star \star *}$ & -0.047 & -0.054 & $-0.292^{*}$ & $-0.298^{*}$ & $-0.750^{* *}$ & $-0.751^{* *}$ & $-0.754^{* *}$ \\
\hline$B_{\text {Skewness }}$ & 0.243 & $-0.588^{\star \star}$ & $-0.294^{*}$ & $-0.656^{\star \star}$ & 0.023 & 0.028 & 0.242 & 0.252 & $0.864^{\star \star}$ & $0.860^{\star \star}$ & $0.863^{\star *}$ \\
\hline B Kurtosis & 0.205 & $-0.517^{\star \star}$ & -0.238 & $-0.527^{\star \star}$ & 0.012 & 0.017 & 0.164 & 0.181 & $0.821^{\star \star}$ & $0.808^{\star \star}$ & $0.812^{\star *}$ \\
\hline$Y_{\text {Mean }}$ & $-0.281^{*}$ & $0.632^{\star \star}$ & 0.250 & $0.610^{\star \star}$ & -0.060 & -0.053 & $-0.313^{\star}$ & $-0.327^{\star}$ & $-0.922^{\star \star}$ & $-0.917^{\star \star}$ & $-0.920^{\star \star}$ \\
\hline $\mathbf{Y}_{\text {Medlan }}$ & $-0.283^{\star}$ & $0.630^{\star \star}$ & 0.258 & $0.630^{\star \star}$ & -0.059 & -0.056 & $-0.304^{*}$ & $-0.314^{*}$ & $-0.899^{\star *}$ & $-0.896^{\star *}$ & $-0.898^{\star *}$ \\
\hline$Y_{\text {Mode }}$ & -0.271 & $0.608^{\star \star}$ & $0.285^{\star}$ & $0.665^{\star \star}$ & -0.056 & -0.051 & $-0.316^{*}$ & $-0.323^{*}$ & $-0.884^{\star \star}$ & $-0.882^{\star *}$ & $-0.884^{\star \star}$ \\
\hline$Y_{\text {Skewness }}$ & 0.229 & $-0.593^{\star *}$ & $-0.305^{\star}$ & $-0.661^{\star \star}$ & 0.005 & 0.010 & 0.239 & 0.250 & $0.858^{\star *}$ & $0.854^{\star *}$ & $0.857^{* *}$ \\
\hline$Y_{\text {Kurtosis }}$ & 0.159 & $-0.508^{\star \star}$ & -0.259 & $-0.524^{\star \star}$ & -0.033 & -0.031 & 0.154 & 0.173 & $0.832^{\star \star}$ & $0.818^{\star \star}$ & $0.822^{\star \star}$ \\
\hline
\end{tabular}

Figure 5 
Spearman correlation coefficient of population canopy CGSD parameters of BFH and microclimate factors. A Spearman correlation analysis of SPSS software was used on 20 CGSD parameters (RMean, RMedian, RMode, RSkewness, RKurtosis, GMean,GMedian,GMode, GSkewness, GKurtosis, BMean, BMedian, BMode, BSkewness, BKurtosis, YMean, YMedian, YMode, YSkewness and YKurtosis) and the microclimate factors including daily meteorological factors (Tdm, RHdm, TGdm, TSdm-10c, VPdm, TDdm, GRdt and PARdt) and photothermal accumulation factors (AT, AGR and APAR) ( $n=51)$. The correlation coefficient obtained by related analysis was drawn to CGSD parameters-daily meteorological factors heat map. The positive correlation coefficient is shown in red, and the negative correlation coefficient is shown in blue. ** indicates significant correlation according to a two-tailed test ( $\mathrm{p} \rrbracket$ $0.01)$, * indicates significant correlation according to a two-tailed test ( $\mathrm{p} \otimes 0.05)$, the same as below.

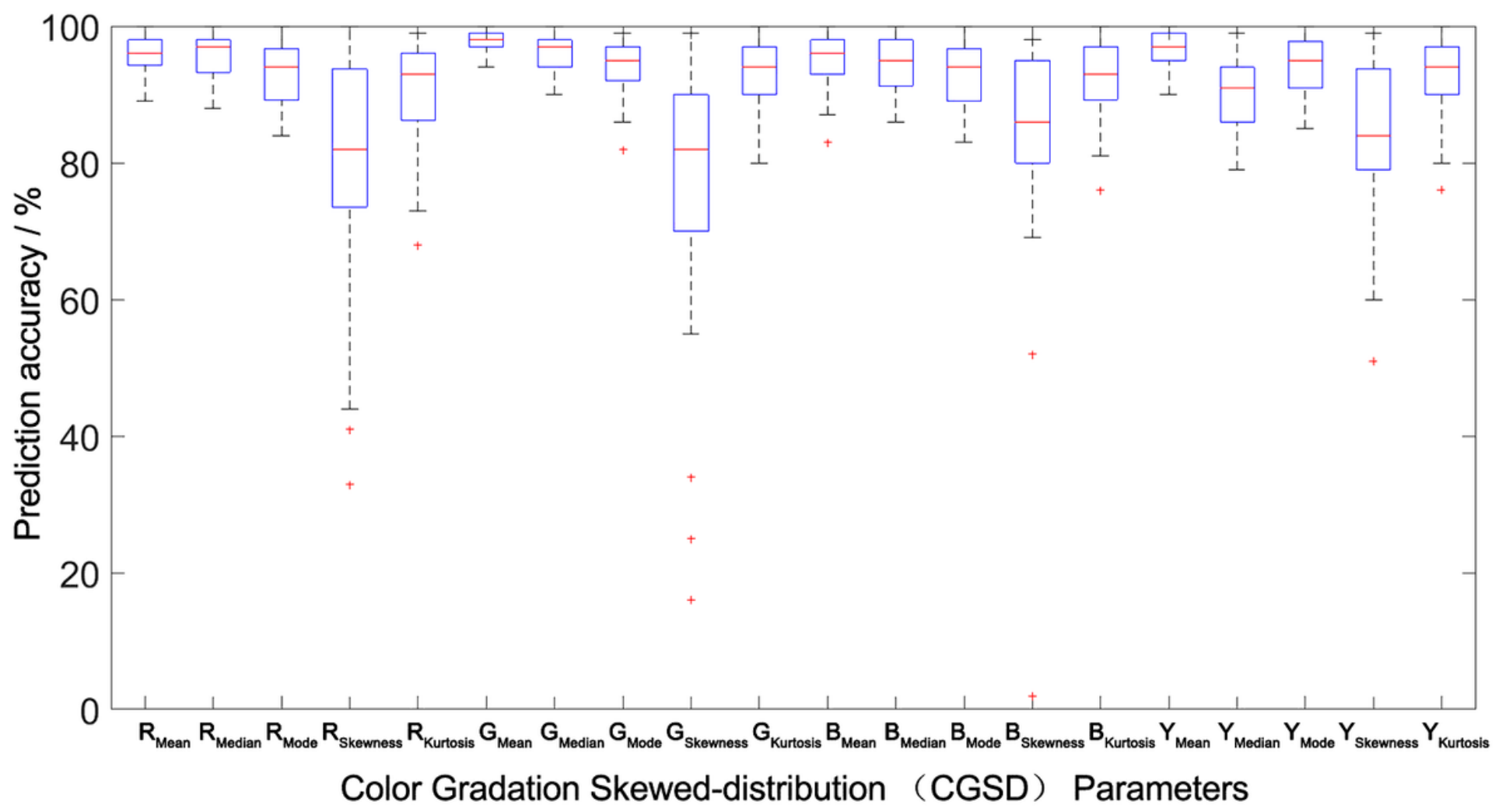

Figure 6

Prediction accuracy interval analysis of the population canopy color-meteorological response models of modeling group. The Boxplot function of MATLAB was used to draw the accuracy percentile distribution diagram of population canopy CGSD parameters prediction model. The blue box in the figure represents the prediction accuracy of the model distributed between $25 \%$ and $75 \%$. The shorter the box, the better the degree of data concentration. The red line in the box represents the median distribution of prediction accuracy, and the dotted line at both ends outside the box represents the endpoint value (maximum and minimum) of the prediction data distribution. The shorter the distance between the two endpoint values, the better the degree of data concentration. The red-cross outside the box represents abnormal data. The fewer abnormal data, the better the degree of data distribution concentration. 


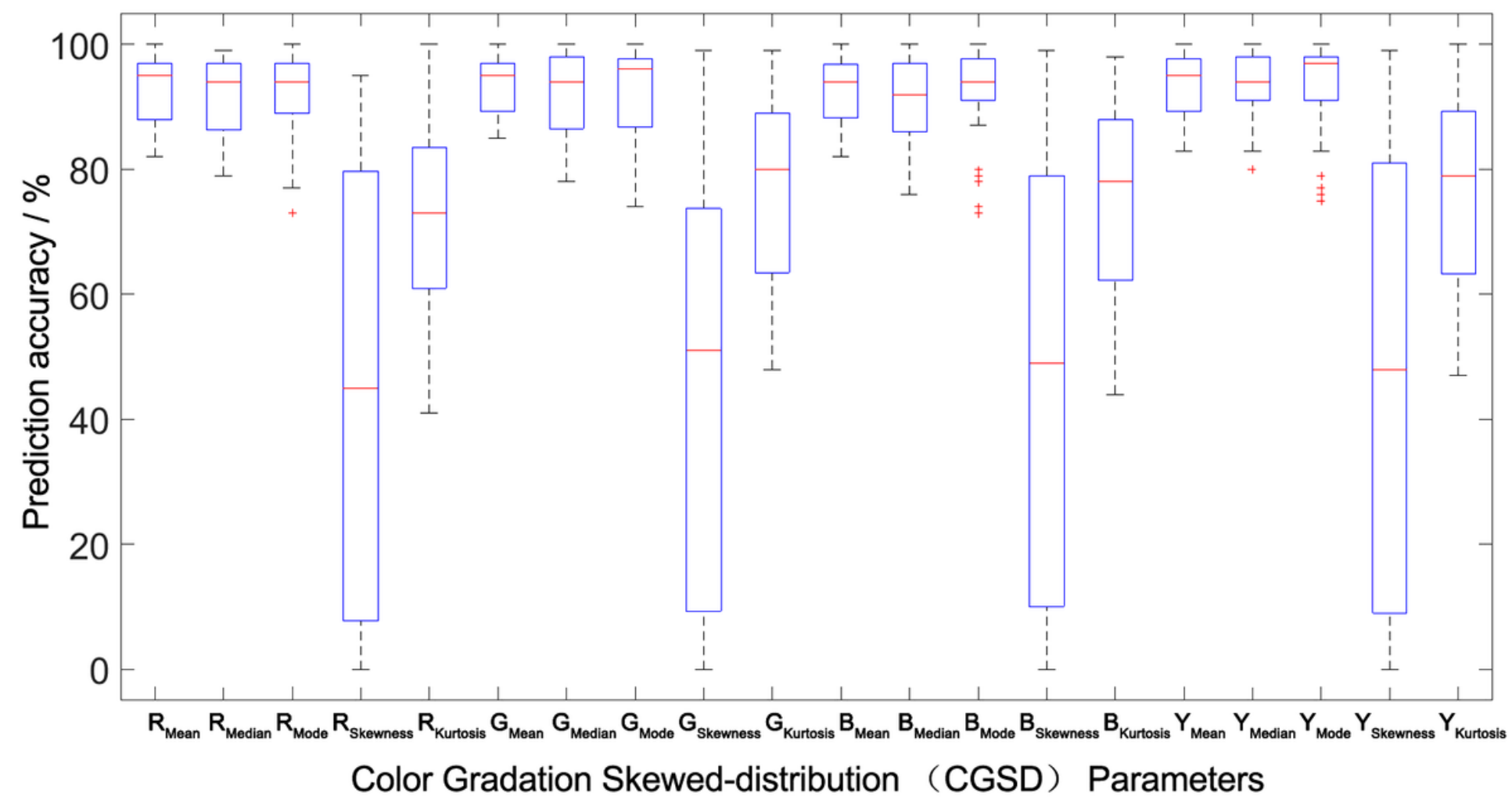

Figure 7

Prediction accuracy interval analysis of the population canopy color-meteorological response models of between-group.

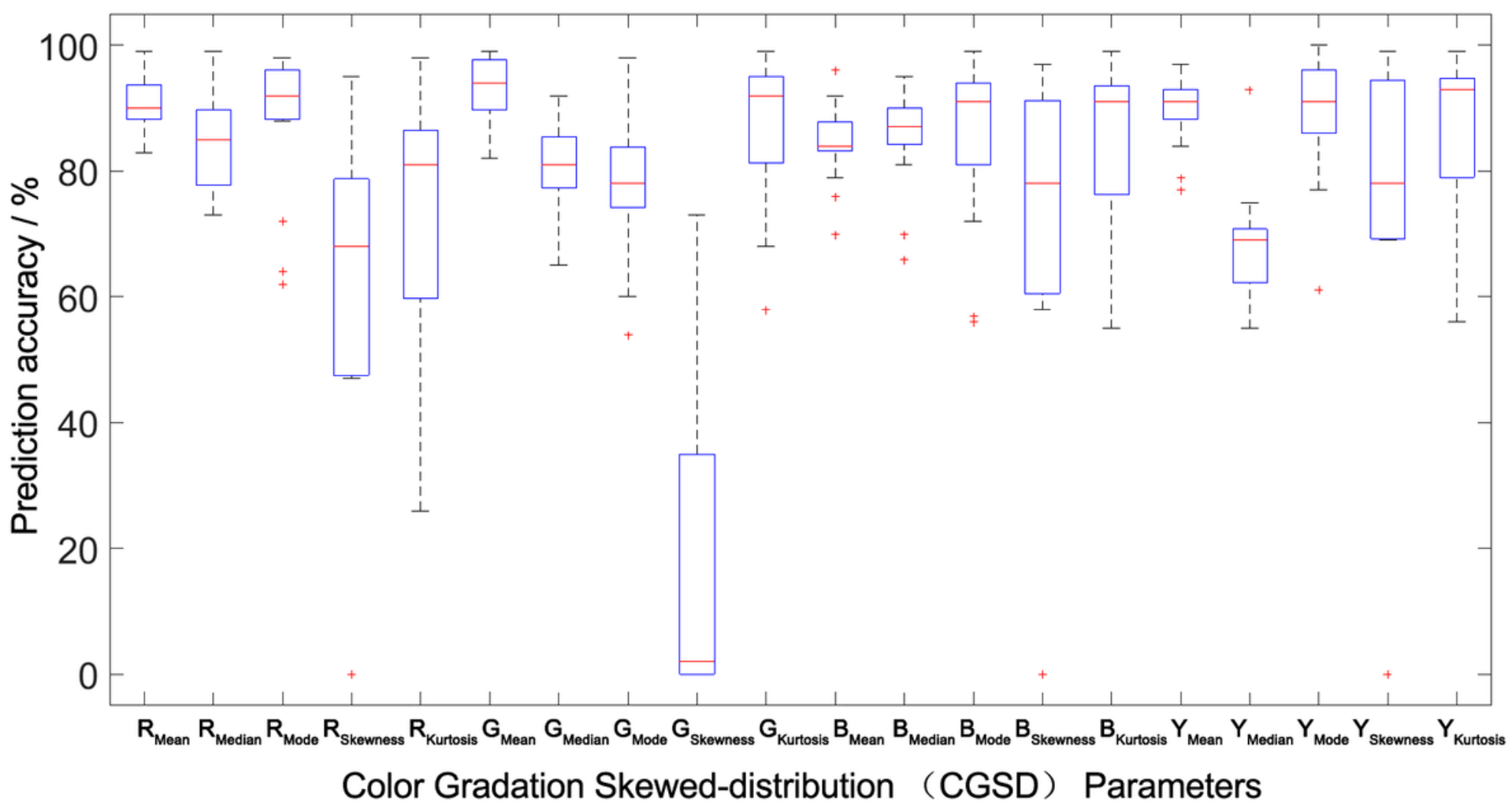

Figure 8

Prediction accuracy interval analysis of the population canopy color-meteorological response models of outside-group. 


\section{Supplementary Files}

This is a list of supplementary files associated with this preprint. Click to download.

- SupplementaryTables1.docx 